\title{
Mulheres e guerras: representações e estratégias
}

Tatiana Moura, Júlia Garraio e Sílvia Roque

\section{(2) OpenEdition}

\section{Journals}

\section{Edição electrónica}

URL: http://journals.openedition.org/rccs/4794

DOI: $10.4000 /$ rccs.4794

ISSN: $2182-7435$

\section{Editora}

Centro de Estudos Sociais da Universidade de Coimbra

Edição impressa

Data de publição: 1 março 2012

Paginação: 05-08

ISSN: 0254-1106

\section{Refêrencia eletrónica}

Tatiana Moura, Júlia Garraio e Sílvia Roque, « Mulheres e guerras: representações e estratégias »,

Revista Crítica de Ciências Sociais [Online], 96 | 2012, posto online no dia 15 fevereiro 2013, consultado o 22 setembro 2020. URL : http://journals.openedition.org/rccs/4794 ; DOI : https://doi.org/10.4000/ rccs. 4794

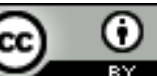




\section{Mulheres e guerras: representações e estratégias}

As estratégias de controlo e ameaça do inimigo e de produção do terror baseadas na construção e manipulação de masculinidades e feminilidades dominantes e subalternas são uma constante em contextos de guerra. As estratégias violentas (físicas, psicológicas, sexuais) de grupos armados (exércitos, guerrilhas, forças policiais, milicias, gangues, fações, cartéis) passam necessariamente pelo controlo das masculinidades e feminilidades, pela promoção de identidades violentas e pelo exercício da violência como forma de terror e controlo das populações, sendo os crimes sexuais e as deslocações forçadas das práticas mais conhecidas e analisadas nestes contextos.

De facto, ainda que mudem os conceitos e as práticas da guerra, o seu carácter sexuado parece ser uma permanência: todas as guerras e conflitos armados assentam na construção de identidades de carácter sexual, e não só, em estruturas e mecanismos de poder e dominação que estão no centro do sistema patriarcal, a que algumas feministas chamam sistema de guerra (Reardon, 1985). Para se perpetuar, este sistema necessita da construção de um determinado tipo de masculinidade (hegemónica, dominante e violenta). Por sua vez, esta masculinidade precisa de masculinidades e feminilidades silenciadas, invisibilizadas e, portanto, marginalizadas, que sejam a sua antitese, negação e contraponto.

Neste número da RCCS, pretendemos contribuir para o aprofundamento da análise sobre representações da violência exercida contra as mulheres e estratégias sexuadas de controlo e poder utilizadas em contextos de guerra. Iniciamos o volume com um ensaio de Carmen Magallón Portolés, "Representaciones, roles, y resistencias, de las mujeres en contextos de violencia", uma reflexão sobre os diversos papéis atribuídos pelos discursos ideológicos às mulheres em situações de violência. Com o intuito de superar imagens essencializadas de vítimas, a autora chama a atenção para a capacidade de ação e de resistência da parte das mulheres em cenários de guerra.

Em "Vamos lá curtir um bocado'. A relação entre identidade sexual, violência e sexualidade em conflitos armados", Gaby Zipfel ensaia uma cartografia de alguns dos principais desafios que se colocam a uma compreensão dos variados fenómenos de violência sexual em conflitos armados, desde a relação entre guerra e a construção/imposição de identidades sexuais, à interseção entre desejo, 
sexualidade e violência, sem deixar de questionar o próprio conceito de guerra como estado de exceção.

Pretendemos analisar igualmente como se processa a memória das vivências das mulheres nas guerras, sobretudo no que tem a ver com violências sexuadas, isto é, por um lado, como as vitimas narram e reconfiguram as suas vidas após essas experiências e, por outro, como comunidades e sociedades que passaram por conflitos armados caracterizados por elevados índices de violência sexual, por exemplo, recordam esses eventos, ou seja, como as experiências individuais transitam, são traduzidas e reconfiguradas na memória pública e nas iconografias nacionais. A partir de estudos de caso, tentaremos identificar instrumentalizações de experiências de violência sexual ao serviço de agendas nacionais e interesses políticos. Paralelamente tentaremos chamar a atenção para os processos de silenciamento a que as vozes das vítimas são sujeitas através destes fenómenos de apropriação coletiva de experiências individuais, descortinando assim possiveis tensões que emergem entre a esfera privada e a esfera pública. Neste contexto, não deixaremos de ter em conta como certas fobias coletivas e manipulações racistas condicionam não só as reações das vitimas de violência sexual como sobretudo a tradução para a esfera pública desses eventos.

Em "Hordas de violadores. A instrumentalização da violência sexual em discursos anticomunistas alemães da Guerra Fria”, Júlia Garraio, através da análise de alguns textos de memórias e de um romance, mostra como as violações de mulheres alemãs por soldados do Exército Vermelho no fim da Segunda Guerra Mundial, ao transitarem para o espaço público, foram recordadas e metaforizadas como emblema de vitimização alemã às mãos do totalitarismo soviético. Longe de ter sido um tema banido da esfera pública na República Federal da Alemanha, essas experiências de violência ajudaram o Estado a definir-se como parte do Ocidente por oposição a um "Leste bárbaro e comunista."

Também o artigo de Teresa Cunba - "As memórias das guerras e as guerras das memórias" - parte da necessidade de distinguir memórias privadas de discursos públicos e oficiais. Através da análise da narração dos sofrimentos femininos em entrevistas a mulheres de Maputo e de Díli que viveram as guerras que assolaram Moçambique e Timor-Leste, a autora problematiza a transfiguração política dessas vivências e os seus possiveis silenciamentos, ao mesmo tempo que questiona e desafia conceções hegemónicas de virilidade em discursos nacionalistas.

Não pretendemos centrar-nos apenas em cenários de guerra 'tradicional', mas também em cenários em que a violência armada assume elevada intensidade, embora os objetivos dos atores destas guerras sejam diferentes dos das 
guerras tradicionais. Tencionamos analisar em que medida o fenómeno da violência sexuada nos ajuda a desvendar possiveis continuidades entre periodos de pré-guerra, guerra e pós-guerra, bem como os contornos das "novíssimas guerras", conceito usado para referir zonas oficialmente em paz mas com niveis e formas de violência armada tradicionalmente associados a situações de guerra (Moura, 2010). Pretende-se, assim, realçar, por um lado, a artificialidade da divisão entre a violência da 'paz' e a violência da 'guerra' (Scheper-Hughes e Bourgois, 2004), e, por outro lado, destacar a transversalidade da manipulação identitária em contextos de violência, seja concentrada e de larga escala, seja disseminada em microespaços e microescalas.

Neste sentido, os três textos que se dedicam a uma análise de situações não convencionais de guerra aliam, a partir de diferentes ângulos e de casos, o estudo de estratégias violentas de controlo e manipulação sexuadas com a análise do papel de representações da violência, de feminilidades e masculinidades na quotidianização e normalização social do sistema de guerra antes mencionado.

No artigo "Lógicas de guerra e a reprodução das margens: gangues, mulheres e violência sexuada em El Salvador", Sílvia Roque centra-se na reprodução da violência sexuada veiculada por representações da violência legítima, desconstrói a conceção da guerra como exceção e questiona a diferenciação entre violências através do prisma da legitimidade e da politização. Demonstra ainda como estas mesmas representações reproduzem a violência em tempos de "paz", do ponto de vista da ocultação e menorização de determinadas experiências da violência, neste caso, das mulheres que se envolvem em gangues violentos. As estratégias de guerra sexuadas não assumem um lugar central neste artigo, são antes incorporadas enquanto expressões possiveis (entre outras) dos mimetismos entre práticas e políticas de guerra e de paz.

Já no artigo "Para além da 'guerra' e da 'paz': territórios de violência em Medellín", Iván Dario Ramírez e Grazielle Costa revelam como algumas das estratégias de atores diversos - governamentais, cartéis, milícias, paramilitares fazem do corpo das mulheres um lugar de esbatimento das fronteiras entre a "guerra" e a "paz". Os autores denunciam a incompreensivel invisibilidade e exclusão das mulheres das políticas de segurança pública de Medellín, apesar de muitas delas experienciarem o sofrimento causado pelo deslocamento intraurbano, feminicídio e violência sexual nesta cidade.

No entanto, nem sempre as mulheres são invisiveis no dominio da segurança pública, como nos demonstra o artigo de Rita Santos, "'Cidadãos de bem' com armas: representações sexuadas de violência armada, (in) segurança e legítima defesa no Brasil". Pelo contrário, a autora demonstra como aos discursos de mobilização durante a campanha para o Referendo sobre a Proibição do 
Comércio de Armas de Fogo e Munições no Brasil correspondem estratégias deliberadas de visibilização e valorização de determinadas representações de bomens e mulheres, masculinidades e feminilidades, de forma a legitimar os argumentos quer a favor, quer contra o microdesarmamento. Santos revela ainda os paralelismos entre os estereótipos sexuados que ocupam o imaginário da guerra e aqueles veiculados num contexto de paz formal.

Finalmente, no artigo "Conexões perdidas: representações de género, violência (armada) e segurança na Resolução 1325”, Rita Santos, Sílvia Roque e Tatiana Moura avançam com uma proposta política concreta para colmatar o enviesamento dos conceitos de género, violência e segurança que a Resolução do Conselho de Segurança das Nações Unidas (2000) sobre Mulheres, Paz e Segurança (1325/2000) reproduz. Utilizando como exemplo de esbatimento entre a guerra e a paz os fenómenos associados à violência armada, defendem uma aplicação mais ampla deste instrumento internacional de forma a "levar a sério o continuum de violências" em contextos de não-guerra ou paz, responsabilizando todos os Estados pela criação, na esfera doméstica, de políticas de prevenção e de combate à violência armada e sexuada.

Tatiana Moura

Júlia Garraio

Sílvia Roque

\section{Referências bibliográficas}

Moura, Tatiana (2010), Novíssimas guerras: espaço, identidades e espirais da violência armada. Coimbra: Almedina.

Reardon, Betty (1985), Sexism and the War System. New York: Teachers College University Press.

Scheper-Hughes, Nancy; Bourgois, Philippe (2004), Violence in War and Peace, an Anthology. Malden: Blackwell Publishing. 